\title{
Experimental study of the shear properties of reinforced ultra-high toughness cementitious composite beams*
}

\author{
Li-jun $\mathrm{HOU}^{1}$, Zhi-yong $\mathrm{LUAN}^{1}$, Da CHEN ${ }^{1}$, Shi-lang XU $\mathrm{X}^{\dagger \neq 2}$ \\ $\left({ }^{1}\right.$ Key Laboratory of Coastal Disaster and Defence of Ministry of Education, Hohai University, Nanjing 210098, China) \\ $\left({ }^{2}\right.$ College of Civil Engineering and Architecture, Zhejiang University, Hangzhou 310058, China) \\ †E-mail: slxu@zju.edu.cn
}

Received Sept. 13, 2014; Revision accepted Jan. 9, 2015; Crosschecked Mar. 23, 2015

\begin{abstract}
This paper presents an experimental investigation into the shear behavior of reinforced ultra-high toughness cementitious composite (UHTCC) beams through flexural tests under a point loading, where UHTCC shows tension strainhardening and multiple cracking characteristics. The varied parameters include shear-span ratios of about 2.06, 3.08, and 4.11, and web reinforcement ratios of $0 \%, 0.25 \%, 0.37 \%$, and $0.55 \%$. The experimental results reveal that reinforced UHTCC (RUHTCC) beams have superior shear resistance compared with reinforced concrete (RC) beams and show stable crack propagation and multiple cracking behaviors in shear. The use of UHTCC as the matrix of beams can serve as a replacement for minimum web reinforcement. A small amount of stirrups used in RUHTCC slender beams results in a more ductile flexure-shear or even flexural failure. However, the use of stirrups in both short beams and RUHTCC slender beams brings little improvement in ultimate shear strength, and thus no shear synergy between UHTCC and stirrups is obtained. A tied-arch model and a truss model can be used to represent the shear mechanism of RUHTCC short and slender beams, respectively. UHTCC web subjected to tension can be considered as inclined tension web members in a truss model for RUHTCC slender beams.
\end{abstract}

Key words: Ultra-high toughness cementitious composite (UHTCC), Shear-span ratio, Stirrups, Shear strength, Diagonal crack, Shear mechanism doi: 10.1631 jzus.A1400274

Document code: A

CLC number: TU317

\section{Introduction}

Fiber reinforced concrete (FRC) shows superior shear resistance and a diagonal crack pattern compared with plain concrete. This is attributed mainly to improved mechanical behavior due to the bridging action of fibers across cracks, including post-cracking tension behavior, aggregate interlocking action, and

\footnotetext{
${ }^{\ddagger}$ Corresponding author

* Project supported by the National Natural Science Foundation of China (No. 51408186), the Natural Science Foundation of Jiangsu Province (Nos. BK20140853 and BK20130843), and the Program of Introducing Talents of Discipline to Universities (No. B12032), China

(D) ORCID: Li-jun HOU, http://orcid.org/0000-0002-5401-0226; Shilang XU, http://orcid.org/0000-0003-4711-0883

(C) Zhejiang University and Springer-Verlag Berlin Heidelberg 2015
}

the dowelling action of longitudinal reinforcement (Narayanan and Darwish, 1987; Li et al., 1992; Kwak et al., 2002; Dinh et al., 2010). A series of equations for predicting the shear strength of steel fiber reinforced concrete (SFRC) beams without stirrups and with different strength concrete and fiber types has been developed through analysis of existing experimental databases (Narayanan and Darwish, 1987; Li et al., 1992; Kwak et al., 2002; Slater et al., 2012; Shahnewaz and Alam, 2014). Note that Shahnewaz and Alam (2014), based on a genetic algorithm, considered the two-way and three-way interactions between parameters for obtaining a good prediction result. However, traditional FRC is characterized by tension strain-softening, and shows a limited enhancement in shear properties such as strength and cracking behavior. 
Ultra-high toughness cementitious composite (UHTCC) (Li et al., 2009), as a kind of high performance fiber reinforced cementitious composite, was designed according to steady-state cracking principles and strain-hardening mechanisms ( $\mathrm{Li}$ and Leung, 1992). UHTCC is also referred to as engineered cementitious composite (ECC) (Li et al., 2001), strainhardening cement based composite (SHCC) (van Zijl and Wittmann, 2011), and ductile fiber reinforced cementitious composite (DFRCC) (Kim et al., 2007). This family of UHTCC material shows apparent tension strain-hardening behavior with an ultimate tensile strain of 3\%-6\%, and excellent crack dispersion capacity, with crack widths below $0.1 \mathrm{~mm}$ in the ultimate tension state (Li V.C. et al., 2001; Li H.D. et al., 2009). Moreover, the basic mechanical properties (Xu and Li, 2008), flexural toughness (Hou et al., 2012), fracture properties (Liu et al., 2012), and durability (Ahmed and Mihashi, 2007; van Zijl and Wittmann, 2011) of UHTCC are superior to those of plain FRC. The structural application of UHTCC has been explored by Kunieda and Rokugo (2006).

The shear properties of UHTCC are important in determining practical applications in shear critical structural members, such as shear walls, coupling beams, beam-column joints, and slab-column joints. In recent years, several experimental studies on the shear behavior of UHTCC have been performed. The experimental results of Li et al. (1994) indicated that the ultimate shear strength of ECC reinforced with $2 \%$ by volume of spectra polyethylene fiber (SPECC) was far higher than that of plain concrete or FRC reinforced with $1 \%$ by volume of steel fiber, and close to that of an RC specimen with a $0.75 \%$ web reinforcement ratio. Shimizu et al. (2004) and van Zijl (2007) showed that shear strength and strain both increased when the volume fraction of fiber in UHTCC increased. Xu et al. (2012) investigated the influence of the shear-span ratio and reinforcement ratio on the shear behavior of RUHTCC beams simply supported. The experimental results revealed that RUHTCC beams showed high shear resistance, stable crack propagation, and different shear transfer mechanisms when the shear-span ratio changed. Moreover, all the RUHTCC beams presented a diagonal multiple cracking pattern and high shear deformation capacity. In addition, a simulation method, based on the smeared and fixed crack approach considering the tensile properties from panel tests, was proposed to predict the shear behavior of RUHTCC members (Suryanto et al., 2010a; 2010b). This model was capable of simulating the shear response of RUHTCC panels and beams well.

Although UHTCC has fine shear capacity, the use of web reinforcement in RUHTCC members is still needed, especially for members with a large shear requirement. However, limited studies have been performed on the coupling effect between UHTCC and stirrups. In contrast, related studies have been conducted concerning the coupling shear mechanism of plain FRC and stirrups. Swamy and Bahia (1979) and Liu (2010) showed that for SFRC beams with a reinforcement ratio of $2 \%-4 \%$, a $0.75 \%-0.8 \%$ volume fraction of steel fiber combined with a small quantity of web reinforcement can result in a ductile yielding behavior. A synergy between fiber and stirrups was shown in (Majdzadeh et al., 2006; Liu, 2010). The maximum load showed $7 \%$ synergy for one beam with a $0.14 \%$ web reinforcement ratio and a $0.5 \%$ volume fraction of steel fiber, and $10 \%$ synergy for another beam with the same stirrup ratio and fraction of synthetic fiber (Majdzadeh et al., 2006).

In this paper, the shear properties of RUHTCC beams with different stirrup ratios and shear-span ratios are investigated. The shear mechanism of RUHTCC beams and the coupling shear effect of UHTCC and stirrups are explored through analysis of crack behavior, shear strength, failure mode and stirrup mechanical behavior compared with that of $\mathrm{RC}$ counterpart beams.

\section{Experimental}

\subsection{Beams}

A total of 14 beams were tested in this study, including eight RUHTCC beams and six RC counterpart beams. All the beams had the same cross section with a depth $(h)$ of $180 \mathrm{~mm}$ and width $(b)$ of $120 \mathrm{~mm}$, and the same cover thickness of $25 \mathrm{~mm}$. The longitudinal reinforcement ratio $(\rho)$ used was $3.25 \%$ for all beams.

The varied parameters were the web reinforcement ratio $\left(\rho_{\mathrm{w}}\right)$ and shear-span ratio $(a / d)$, where $a$ is the shear span length and $d$ denotes the effective depth of the cross section. The span lengths $(l)$ were designed as 300,450 , and $600 \mathrm{~mm}$, which corresponded to shear-span ratios of $2.06,3.08$, and 4.11, 
respectively. Also, the lengths of the beams were 850 , 1150 , and $1450 \mathrm{~mm}$ with a free length of $125 \mathrm{~mm}$ outside of two supports. The stirrup ratios were taken as $0 \%, 0.25 \%, 0.37 \%$, and $0.55 \%$. The last three stirrup ratios had stirrup spacings of 225,150 , and $100 \mathrm{~mm}$, respectively. For RUHTCC beams with a shear-span ratio of 3.08 , these four types of stirrup ratios were used, whereas only two stirrup ratios of $0 \%$ and $0.37 \%$ were used for the remaining series. Note that in the case of a web reinforcement ratio of $0.37 \%$, the corresponding stirrup spacing of $150 \mathrm{~mm}$ corresponds to the maximum detailing stirrup spacing suggested in Chinese code GB50010-2010 (SAC, 2010). The geometry and reinforcement configurations of beams are shown in Fig. 1, and details of the beams are summarized in Table 1.

Based on different variable parameters, the beam characteristics can be simply described. The materials of concrete and UHTCC are denoted by $\mathrm{C}$ and $\mathrm{U}$, respectively. The shear-span ratio used is simplified as the corresponding integer 2,3 , or 4 . The four web reinforcement ratios are represented by w0 $(0 \%)$, wl (low ratio of $0.25 \%$ ), wm (middle ratio of $0.37 \%$ ), and wh (high ratio of $0.55 \%$ ). Therefore, a RUHTCC beam with shear-span ratio of 3.08 and a web reinforcement ratio of $0.25 \%$ is denoted by U3-wl. In addition, beams with a shear-span ratio of 2.06 are termed short beams, while those with a shear-span ratio of 3.08 or 4.11 are termed slender beams.

\subsection{Material properties}

The mass mixture proportion of concrete used was $m$ (cement): $m$ (water): $m$ (sand): $m$ (coarse aggregate) $=1: 0.535: 1.563: 2.900$. The sand used in the concrete had a grain size range of $0.35-2 \mathrm{~mm}$ and coarse aggregate was about $25 \mathrm{~mm}$ in grain size. The mortar matrix of UHTCC was made from plain cement, water, fine sand, mineral addition, and superplasticizer. A volume fraction of $2 \%$ of polyvinyl alcohol (PVA) fiber was used as the reinforcement fiber. This type of PVA fiber has a diameter of $0.04 \mathrm{~mm}$, a length of $12 \mathrm{~mm}$, a tensile strength of $1600 \mathrm{MPa}$, and a tensile elastic modulus of $40 \mathrm{GPa}$.

Concrete compressive strength $f_{\text {cu }}$ and splitting tensile strength $f_{\text {sp }}$ were tested using cube specimens of $150 \mathrm{~mm}$ in dimension. The uniaxial tension property of UHTCC was tested using thin plate specimens $350 \mathrm{~mm}$ long, $50 \mathrm{~mm}$ wide, and $15 \mathrm{~mm}$ thick. The tested tensile stress-strain curves (Fig. 2) show the apparent tensile strain-hardening behavior. The compressive strength of UHTCC was measured using $70.7 \mathrm{~mm}^{3}$ specimens, and the splitting tensile strength was obtained using $100 \mathrm{~mm}^{3}$ specimens. The tested mechanical properties of concrete and UHTCC are summarized in Table 1.

Deformed rebar with a diameter of 18 and $20 \mathrm{~mm}$ was used for longitudinal tension reinforcement. The stirrup used was made of smooth rebar with a diameter of $6.5 \mathrm{~mm}$, and the longitudinal detailing reinforcement in the compression zone was a smooth steel bar with a diameter of $6.5 \mathrm{~mm}$. The yielding strength $\left(f_{\mathrm{y}}\right)$ and ultimate tensile strength $\left(f_{\mathrm{u}}\right)$ of the rebar were tested according to the Chinese code GB/T228-2002 (SAC, 2002). The test results are listed in Table 2.

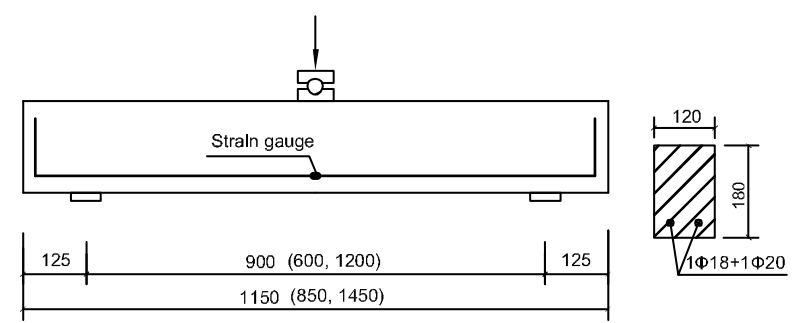

(a)

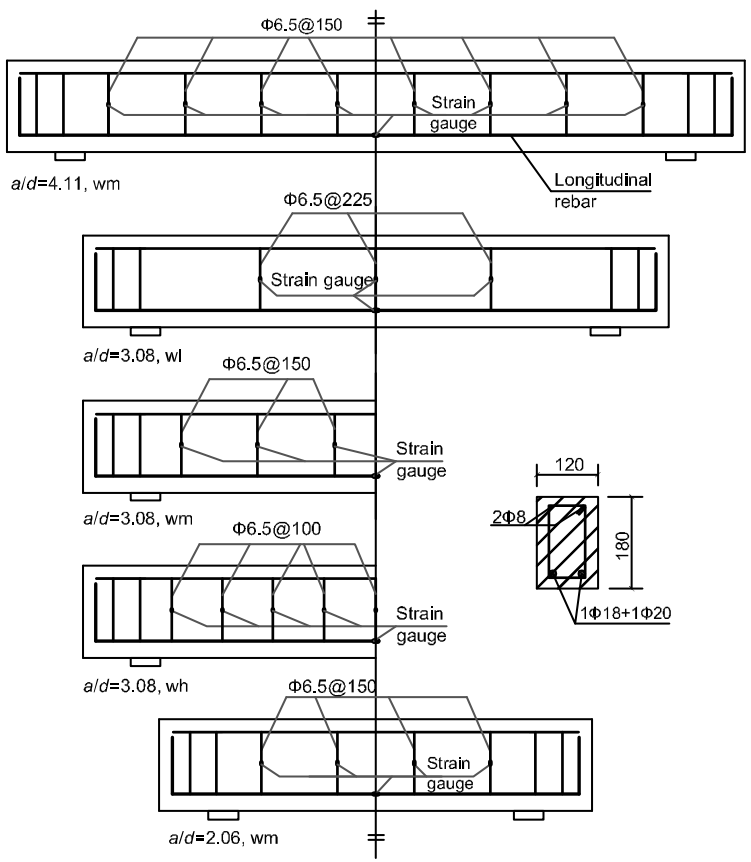

(b)

Fig. 1 Geometry and reinforcement configuration of beams tested without stirrups (a) and with stirrups (b) (unit: $\mathbf{m m}$ )

The values in brackets denote the size corresponding to beams with an a/d of 2.06 and 4.11, respectively (the same below) 
Table 1 Tested mechanical properties of concrete and UHTCC

\begin{tabular}{lccccclcc}
\hline Beam & $l(\mathrm{~mm})$ & $b(\mathrm{~mm})$ & $d(\mathrm{~mm})$ & $a / d$ & $\rho(\%)$ & $\rho_{\mathrm{w}}(\%)$ & $f_{\text {cu }}(\mathrm{MPa})$ & $f_{\text {sp }}(\mathrm{MPa})$ \\
\hline C2-w0 & 600 & 120 & 146 & 2.06 & 3.25 & 0 & $48.85 \pm 2.44$ & $3.55 \pm 0.21$ \\
C2-wm & 600 & 120 & 146 & 2.06 & 3.25 & 0.37 & $48.85 \pm 2.44$ & $3.55 \pm 0.21$ \\
U2-w0 & 600 & 120 & 146 & 2.06 & 3.25 & 0 & $46.59 \pm 1.86$ & $5.89 \pm 0.23$ \\
U2-wm & 600 & 120 & 146 & 2.06 & 3.25 & 0.37 & $46.59 \pm 1.86$ & $5.89 \pm 0.23$ \\
C3-w0 & 900 & 120 & 146 & 3.08 & 3.25 & 0 & $48.85 \pm 2.44$ & $3.55 \pm 0.21$ \\
C3-wm & 900 & 120 & 146 & 3.08 & 3.25 & 0.37 & $48.85 \pm 2.44$ & $3.55 \pm 0.21$ \\
U3-w0 & 900 & 120 & 146 & 3.08 & 3.25 & 0 & $45.73 \pm 1.51$ & $5.89 \pm 0.23$ \\
U3-w1 & 900 & 120 & 146 & 3.08 & 3.25 & 0.25 & $45.73 \pm 1.51$ & $5.89 \pm 0.23$ \\
U3-wm & 900 & 120 & 146 & 3.08 & 3.25 & 0.37 & $45.73 \pm 1.37$ & $6.07 \pm 0.25$ \\
U3-wh & 900 & 120 & 146 & 3.08 & 3.25 & 0.55 & $45.73 \pm 1.37$ & $6.07 \pm 0.25$ \\
C4-w0 & 1200 & 120 & 146 & 4.11 & 3.25 & 0 & $48.85 \pm 2.44$ & $3.55 \pm 0.21$ \\
C4-wm & 1200 & 120 & 146 & 4.11 & 3.25 & 0.37 & $48.85 \pm 2.44$ & $3.55 \pm 0.21$ \\
U4-w0 & 1200 & 120 & 146 & 4.11 & 3.25 & 0 & $45.73 \pm 1.37$ & $6.07 \pm 0.25$ \\
U4-wm & 1200 & 120 & 146 & 4.11 & 3.25 & 0.37 & $45.73 \pm 1.37$ & $6.07 \pm 0.25$ \\
\hline
\end{tabular}

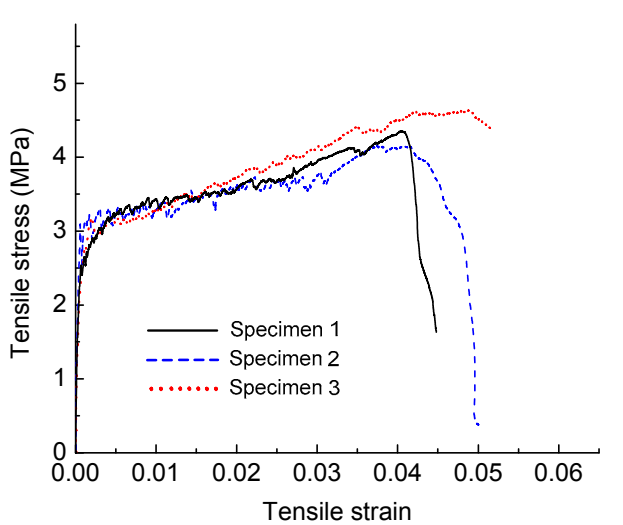

Fig. 2 Uniaxial tensile stress-strain curves of UHTCC

Table 2 Tensile strength of rebar

\begin{tabular}{ccc}
\hline Rebar & $f_{\mathrm{y}}(\mathrm{MPa})$ & $f_{\mathrm{u}}(\mathrm{MPa})$ \\
\hline$\Phi 6.5$ & $316 \pm 6.36$ & $450 \pm 8.85$ \\
$\Phi 18$ & $392 \pm 5.21$ & $554 \pm 9.32$ \\
$\Phi 20$ & $350 \pm 4.35$ & $520 \pm 8.45$ \\
\hline
\end{tabular}

\subsection{Fabrication and curing}

All the beams were cast in a plywood mold, and all the comparison specimens for measuring the material mechanical properties were made at the same time. Layer casting and vibration techniques were used for obtaining a fine compactness, where each layer was taken as half the depth of the beams. After casting, a layer of plastic membrane was used to cover the beams and comparison specimens to reduce the loss of water. Afterwards, the beams were further covered by a grass curtain and cured outside by watering them three times a day to maintain humid conditions. The comparison specimens were cured in the same environment as that of the beams.

\subsection{Test instruments and program}

The shear tests were conducted on a $10000 \mathrm{kN}$ electronic universal test machine. All the beams were simply supported and subjected to a concentrated loading at the mid-span point. A load cell with a maximum measurement capacity of $300 \mathrm{kN}$ was used to minimize the test error. Two pairs of linearly variable differential transformers (LVDTs) were fixed at the supports and at mid-span locations. The net deflection was taken as the difference between the displacement at mid-span and at the supports. Another pair of LVDTs was arranged diagonally in the web of the shear span region to obtain the total diagonal crack opening. The detailed arrangements of the loading and test set-ups are shown in Fig. 3.

The beams were loaded through the coupled load and displacement control mode. The load was applied in increments of 3-7 kN, e.g., $3 \mathrm{kN}$ for $\mathrm{RC}$ beam $\mathrm{C} 4-\mathrm{w} 0$ and $7 \mathrm{kN}$ for beams with an a/d ratio of 2.06 . During every loading increment, the manual displacement control mode was used, and the displacement rate was about $0.10-0.15 \mathrm{~mm} / \mathrm{min}$. For beams showing flexural yielding, a higher rate of 0.30 $0.40 \mathrm{~mm} / \mathrm{min}$ was used after the yielding of the longitudinal reinforcement. When the integer time of load increment was reached, the applied load 
remained for about $5 \mathrm{~min}$ to allow time to mark the crack propagation pattern and measure the diagonal crack width using a crack observation apparatus with a precision of $0.02 \mathrm{~mm}$.

Electric resistance strain gauges with a gauge length of $2 \mathrm{~mm}$ were attached to longitudinal tension rebar at the mid-span location to monitor strain development. Also, strain gauges were attached to stirrups at the mid-depth location to study the behavior of confining reinforcement. All the test data were

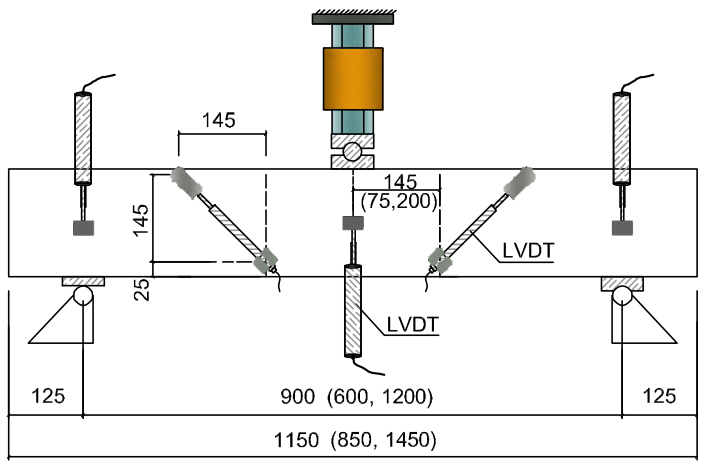

Fig. 3 Arrangement of test and loading set-ups (unit: mm) collected synchronously using an dynamic data acquirement system connected to a computer.

\section{Results and discussion}

\subsection{Shear crack characteristics}

Fig. 4 shows the crack pattern of test beams at the ultimate shear failure. All the beams showed a critical diagonal crack, except for beams C4-wm, U4-wm, and U3-wh with a final critical flexural crack. A diagonal multiple cracking mode appeared in all the RUHTCC beams regardless of the shear-span ratio and web reinforcement ratio, whereas RC beams had only 1-2 diagonal cracks. Therefore, the use of UHTCC with tensile strain-hardening and fine crack dispersion capacities apparently improves the shear behavior of beams. Comparing the crack pattern in RUHTCC short beams $(a / d=2.06)$ and slender beams ( $a / d=3.08$ and 4.11 ), on the short beams the diagonal cracks propagated almost in a line from the support to the loading point, whereas on the slender beams many more diagonal cracks were distributed almost in parallel in the shear span region.
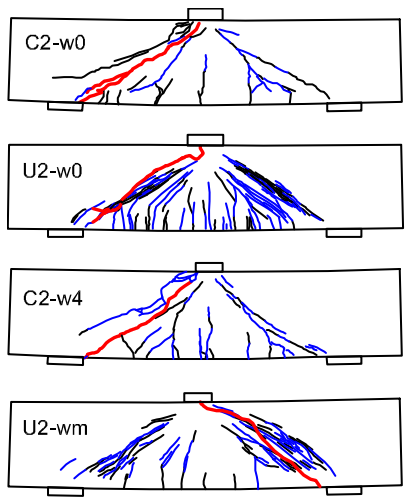

(a)
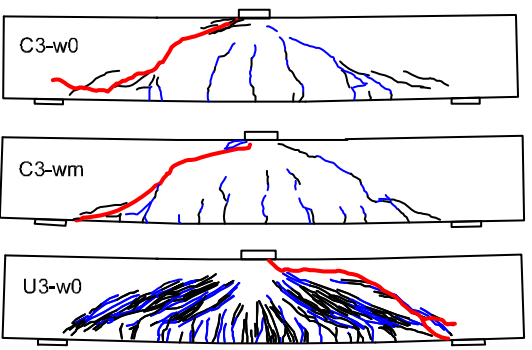

(c)

Fig. 4 Crack patterns at the ultimate failure: (a) $a / d=2.06$; (b) $a / d=4.11 ;$ (c) $a / d=3.08$
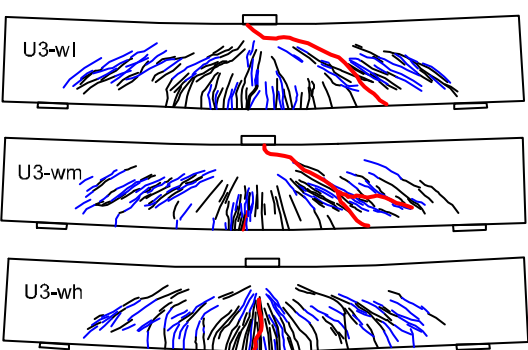

(c) 
RC slender beams without stirrups had an apparent interface splitting crack along the longitudinal reinforcement (Figs. $4 \mathrm{~b}$ and $4 \mathrm{c}$ ), a feature considered to be a trigger of unstable shear crack propagation (Kim and White, 1999), while the use of detailing web rebar effectively limited the formation of this type of crack. However, the short beams and all the RUHTCC beams showed none of this type of splitting crack along the longitudinal steel bar. Note that the mechanical mechanisms differ: the confinement of the support reaction in short beams greatly limits the development of a splitting crack, whereas the outstanding mechanical properties of UHTCC are mainly responsible for this phenomenon in RUHTCC beams. In RUHTCC beams, although a number of diagonal cracks interacted with the reinforcement, the tensile stress carried by UHTCC was maintained due to the bridging connection action of fibers across the cracks and the tensile confinement of strain-hardening characteristic. Thus, no stress concentration formed at the point of interaction between the diagonal crack and the rebar. Consequently, the relative slip between UHTCC and reinforcement was eliminated and the deformation compatibility between them was ensured, leading to stable shear crack development in RUHTCC beams.

The comparison between the crack patterns of RUHTCC beams with different transverse reinforcement ratios shows that with an increase in stirrup ratio, the number of inclined cracks gradually decreases in slender beams, whereas the trend seems unclear in short beams. The elastic modulus of stirrups is far larger than that of UHTCC after cracking, and therefore the stirrup in the web may confine the development of diagonal cracks. However, for the short beams with a shear span length of $2.06 \mathrm{~d}$, the transverse detailing stirrups were located near the two ends of inclined cracks, which may have resulted in only a relatively slight confinement of crack development.

Fig. 5 shows the change in the maximum crack width with the increase in applied load. RUHTCC beams showed a stable diagonal crack propagation and had a maximum crack width of $0.3 \mathrm{~mm}$ for short beams and $0.2 \mathrm{~mm}$ for slender beams, whereas the maximum crack width was high up to $1.2 \mathrm{~mm}$ for RC counterpart beams. This advantage can be attributed to the prominent crack control capacity of UHTCC itself. Moreover, the web reinforcement had almost no effect on the maximum diagonal crack width for RUHTCC beams. In contrast, the transverse rebar used in RC beams resulted in a small reduction of the maximum crack width from $1.25 \mathrm{~mm}$ to $0.96 \mathrm{~mm}$. As a result, the maximum diagonal crack width was dependent mainly on the crack control capacity of the material itself rather than on the web stirrup provided. Note that the use of stirrups in an RC beam with an a/d of 3.08 (Fig. 5b) could not apparently slow down the increase in diagonal crack width. This was mainly because the principal diagonal crack in the beam web resulted in the yielding of the stirrup, and the confinement effect on the shear crack was weakened greatly. At a crack width of $0.1 \mathrm{~mm}$ (Fig. 5), the corresponding load was larger than the so-called ultimate service load (taken as $0.6 P_{\mathrm{u}}$, where $P_{\mathrm{u}}$ is the ultimate load) (Xu et al., 2012) for all the RUHTCC beams. In other words, the diagonal crack width at the service load is expected to be lower than $0.1 \mathrm{~mm}$, which satisfies the required crack width limitation in a harsh environment.
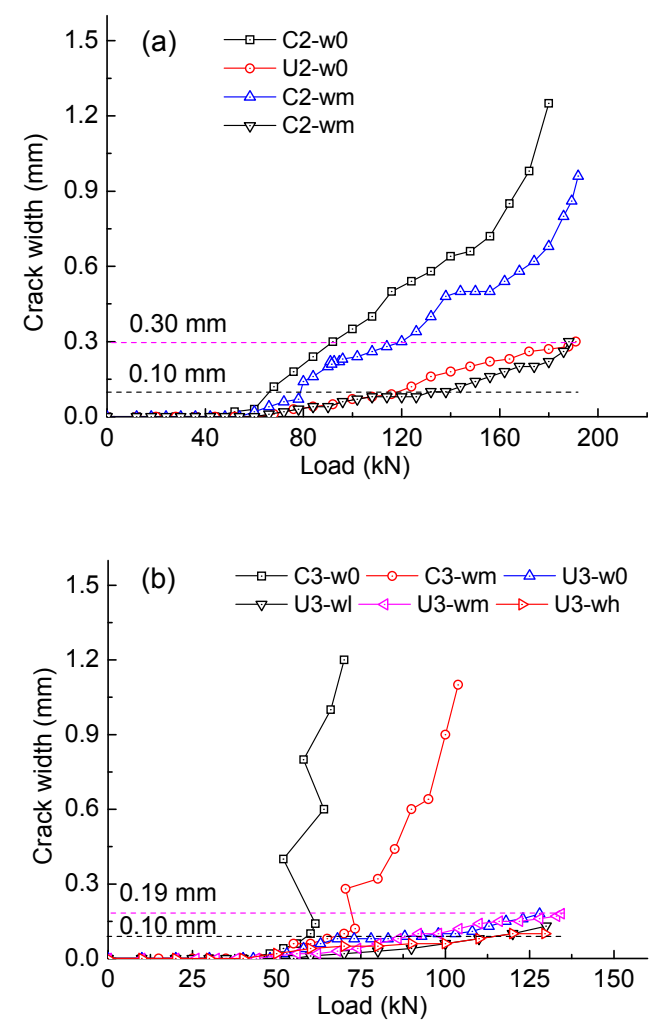

Fig. 5 Evolution of the maximum diagonal crack width for tested beams: (a) short beams with an a/d of 2.06; (b) slender beams with an a/d of 3.08 
Fig. 6 compares the total diagonal crack opening ( $\left.w_{\text {total }}\right)$ for all the beams. Beams with stirrups had a smaller total diagonal crack opening than beams without stirrups, except for beam C4-w0. This phenomenon further demonstrates the confinement effect of stirrups on the propagation of diagonal cracks. Moreover, the slender beams with an a/d of 4.11 showed a large difference in the $w_{\text {total }}$, while the remaining series of beams with the same shear-span ratio and stirrup ratio had a similar $w_{\text {total }}$. In the case of beams with an a/d of 4.11, RUHTCC beam U4-w0 had the maximum value of $w_{\text {total }}$, followed by RUHTCC beam U4-wm, and RC beams C4-wm and C4-w0. This arose mainly from the difference in failure characteristics. Beam U4-w0 showed final shear failure with apparent diagonal crack development, while beams U4-wm and C4-wm presented final flexure failure with limited diagonal crack propagation, and beam $\mathrm{C} 4-\mathrm{w} 0$ showed an immediate shear failure at the shear cracking without the development of diagonal cracks.

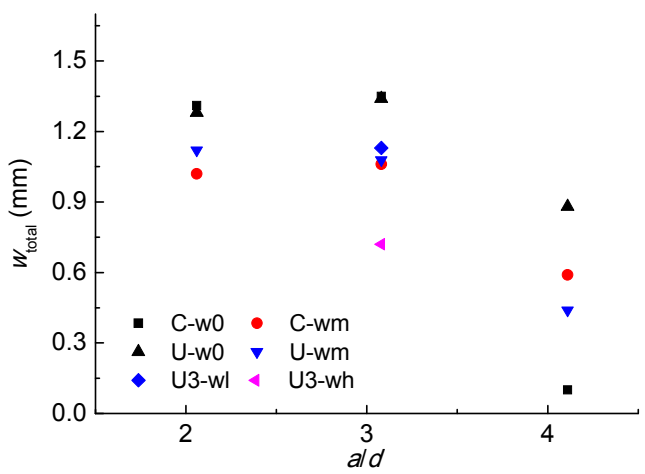

Fig. 6 Comparison of total diagonal crack opening $w_{\text {total }}$

Comparing the total diagonal crack opening in Fig. 6 and the maximum diagonal crack width in Fig. 5, note that the two values are almost equal for $\mathrm{RC}$ beams with the same shear-span ratios of 2.06 and 3.08 due to the development of a single macro diagonal crack, whereas the total crack opening is the sum of the crack width of all the diagonal cracks for RUHTCC beams. This further demonstrates the excellent crack dispersion capacity of UHTCC in shear.

\subsection{Load-deflection behavior}

Fig. 7 shows the load-deflection curves of the beams. The flexural stiffness of RC beams was slightly higher than that of RUHTCC beams with the same parameters, whereas the stiffness of beams appeared to decrease with an increase in shear-span ratio from 2.06 to 4.11 . Beams with stirrups had larger stiffness than those without stirrups. This implies that both the shear-span ratio and stirrup ratio affect the load-deflection behavior of beams. In particular, the shear-span ratio seems to play a controlling role.
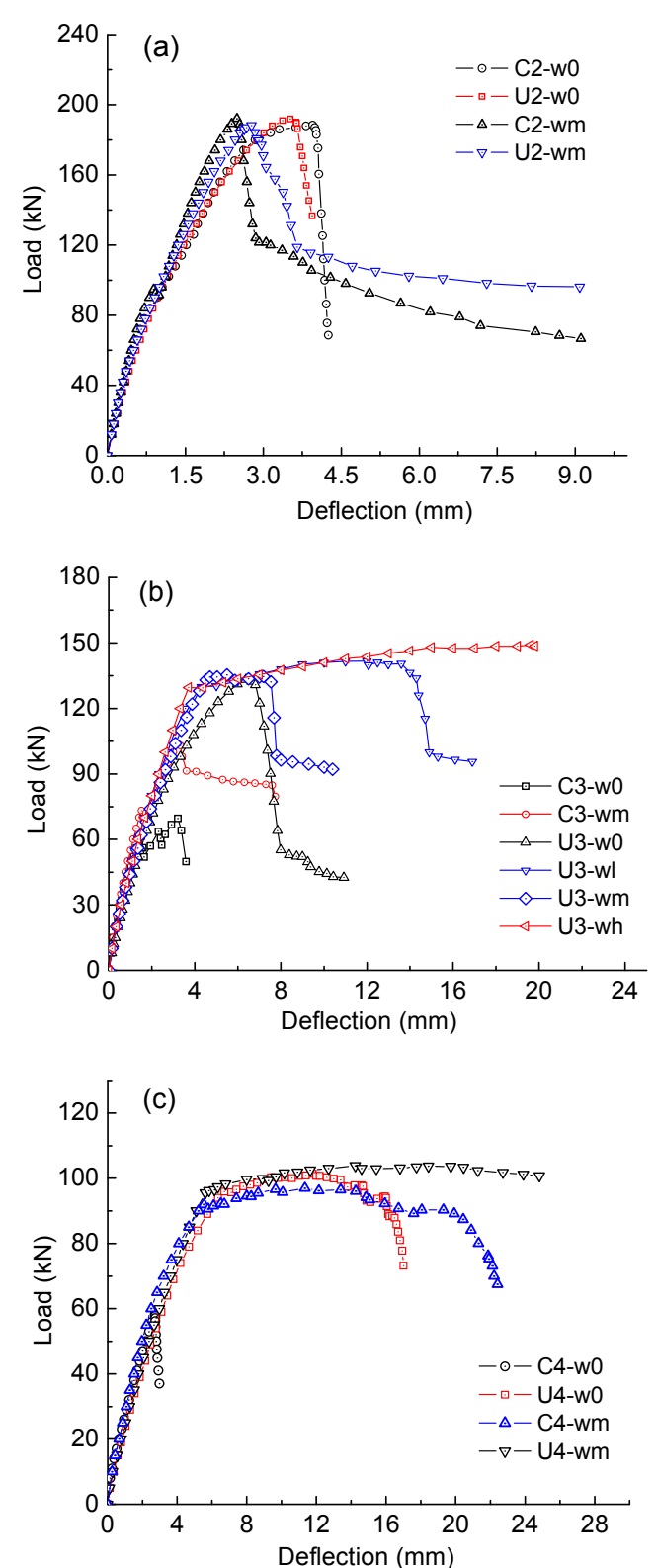

Fig. 7 Load-deflection curves of beams tested: (a) $a / d=$ 2.06; (b) $a / d=3.08$; (c) $a / d=4.11$

All the beams showed linear load-deflection behavior in the initial stage, while nonlinear characteristics became more apparent after shear cracking, 
especially for RC beams. All the RUHTCC beams showed stable and continuous load increases with deflection up to the ultimate failure, and the development of shear cracks did not result in an abrupt load drop. This can be attributed to the elimination of interface splitting cracks along the longitudinal reinforcement and outstanding tension capacity in the post-cracking stage. The fine crack control capability of UHTCC avoids the formation of a principal diagonal crack, which would lead to a redistribution of shear stress prior to the peak load. In contrast, RC short beams and slender beams with stirrups presented relatively stable load-deflection behavior, but showed a slight load drop due to stress redistribution at the formation of the principal diagonal crack.

Based on load-deflection and cracking behavior, failure modes can be divided into two main categories: shear failure showing critical shear cracks, and flexural failure (F) with only flexural principal cracks. Shear failure can be sub-divided into shear failure prior to yielding of the longitudinal steel bar and flexure-shear failure (FS) after yielding, according to the load-deflection behavior. Further, based on shear crack evolution patterns, there are three kinds of failure modes for shear failure prior to yielding: diagonal tension failure (DT), showing direct failure once shear cracking occurs, shear tension failure (ST), showing a coupled interface splitting crack along the longitudinal reinforcement and the crush of the matrix material in the compression zone, and shear compression failure (SC), showing the crush of matrix in the compression zone and the occurrence of a critical shear crack without an interface splitting crack. Table 3 summarizes the detailed failure modes for all the beams.

The use of stirrups has an apparent influence on the failure mode and load-deflection behavior. For RC slender beams, the provision of detailing stirrups can transform the shear tension or diagonal tension failure modes into shear compression failure or even ductile flexural failure. For RUHTCC slender beams, the application of a low web rebar ratio of from $0.25 \%$ to $0.55 \%$ transforms shear compression failure into ductile flexure-shear failure or flexure failure for beams with an a/d of 3.08. The use of detailing stirrups changes the flexure-shear failure to flexure failure for beams with an a/d of 4.11. For short beams, although the use of stirrups cannot change the failure mode, the descending branch in the post-peak stage becomes gentler (Fig. 7a).

Although beams failing in flexure-shear and flexure show apparent flexural yielding deformation, the ductility index needs to be estimated $\left(\delta_{\mathrm{u}} / \delta_{\mathrm{y}}, \delta_{\mathrm{y}}\right.$ is the yielding deflection and $\delta_{\mathrm{u}}$ is the ultimate deflection). The calculated results are listed in Table 3. RUHTCC beams failing in flexure had a high ductility index up to $4.28-5.28$, beyond the ductility index of 3.0 suggested in seismic design (Shuaib and Ray, 1991). However, other beams showing flexural yielding had ductility indexes ranging from 1.63 to 2.95 , slightly lower than the suggested ductility requirement. Therefore, moderate web reinforcement

Table 3 Experimental results of test beams

\begin{tabular}{lccccccccc}
\hline Beam & $\begin{array}{c}v_{\text {cr }} \\
(\mathrm{MPa})\end{array}$ & $\begin{array}{c}V_{\mathrm{u}} \\
(\mathrm{kN})\end{array}$ & $\begin{array}{c}v_{\mathrm{u}} \\
(\mathrm{MPa})\end{array}$ & $\begin{array}{c}\delta_{\mathrm{u}} \\
(\mathrm{mm})\end{array}$ & $\delta_{\mathrm{u}} / \delta_{\mathrm{y}}$ & $v_{\mathrm{u}} / v_{\mathrm{cr}}$ & $\begin{array}{c}w_{\text {total }} \\
(\mathrm{mm})\end{array}$ & $\begin{array}{c}\varepsilon_{\mathrm{w}} \\
(\mu \mathrm{m} / \mathrm{m})\end{array}$ & $\begin{array}{c}\text { Failure } \\
\text { mode }\end{array}$ \\
\hline C2-w0 & 1.89 & 94.16 & 5.37 & 3.94 & - & 2.84 & 1.31 & - & $\mathrm{SC}$ \\
C2-wm & 1.78 & 96.00 & 5.48 & 2.55 & - & 3.36 & 1.02 & 2175 & $\mathrm{SC}$ \\
U2-w0 & 1.94 & 95.86 & 5.47 & 3.53 & - & 2.82 & 1.28 & - & $\mathrm{SC}$ \\
U2-wm & 1.88 & 94.10 & 5.37 & 2.77 & - & 2.86 & 1.12 & 1535 & $\mathrm{SC}$ \\
C3-w0 & 1.75 & 34.79 & 1.99 & 3.36 & - & 1.13 & 1.21 & - & $\mathrm{ST}$ \\
C3-wm & 1.55 & 51.90 & 2.96 & 3.21 & - & 1.91 & 1.06 & Failure & SC \\
U3-w0 & 1.51 & 66.60 & 3.80 & 6.49 & - & 2.52 & 1.34 & - & SC \\
U3-w1 & 1.86 & 70.55 & 4.03 & 12.50 & 2.95 & 2.16 & 1.13 & 2210 & SC \\
U3-wm & 1.51 & 67.62 & 3.86 & 7.21 & 1.63 & 2.56 & 1.08 & 1800 & FS \\
U3-wh & 1.57 & 74.55 & 4.26 & 19.60 & 5.28 & 2.71 & 0.72 & 1250 & F \\
C4-w0 & 1.66 & 29.15 & 1.66 & 2.72 & - & 1.00 & 0.10 & - & DT \\
C4-wm & 1.53 & 48.50 & 2.77 & 14.28 & 2.74 & 1.81 & 0.59 & 1703 & F \\
U4-w0 & 1.63 & 50.67 & 2.89 & 12.48 & 1.96 & 1.77 & 0.88 & - & FS \\
U4-wm & 1.57 & 51.87 & 2.96 & 24.82 & 4.28 & 1.89 & 0.44 & 1487 & F \\
\hline
\end{tabular}

$v_{\mathrm{cr}}$ is the cracking shear strength; $V_{\mathrm{u}}$ is the ultimate shear force; $v_{\mathrm{u}}$ is the ultimate shear strength; and $\varepsilon_{\mathrm{w}}$ is the maximum strain of stirrups at the peak load or the flexural yielding of the beam 
needs to be provided to obtain adequate flexural ductility or even flexure failure for an actual engineering structure.

\subsection{Mechanical behavior of web reinforcement}

It is well known that the direct shear transfer of stirrups is the most important factor for improving the shear resistance of beams. To investigate the shear transfer behavior of web stirrups, the evolution of stirrup strain with the applied load was investigated for four beams, U2-wm, C2-wm, U3-wm, and C3-wm, representing a comparison of RUHTCC and RC short and slender beams with a stirrup ratio of $0.37 \%$. The development of stirrup strain in the left and right shear span was not symmetric, especially with a faster strain increase after the formation of the principal diagonal crack (Fig. 8). During loading from $50 \mathrm{kN}$ to $75 \mathrm{kN}$, the stirrup strain showed a large increase mainly due to the occurrence of shear cracking at this stage. Moreover, for RC beam C3-wm, the stirrup at about $225 \mathrm{~mm}$ from the mid-span reached the yielding state, showing a drastic increase in strain (Fig. 8c). However, the stirrups in other beams did not show this yielding phenomenon.
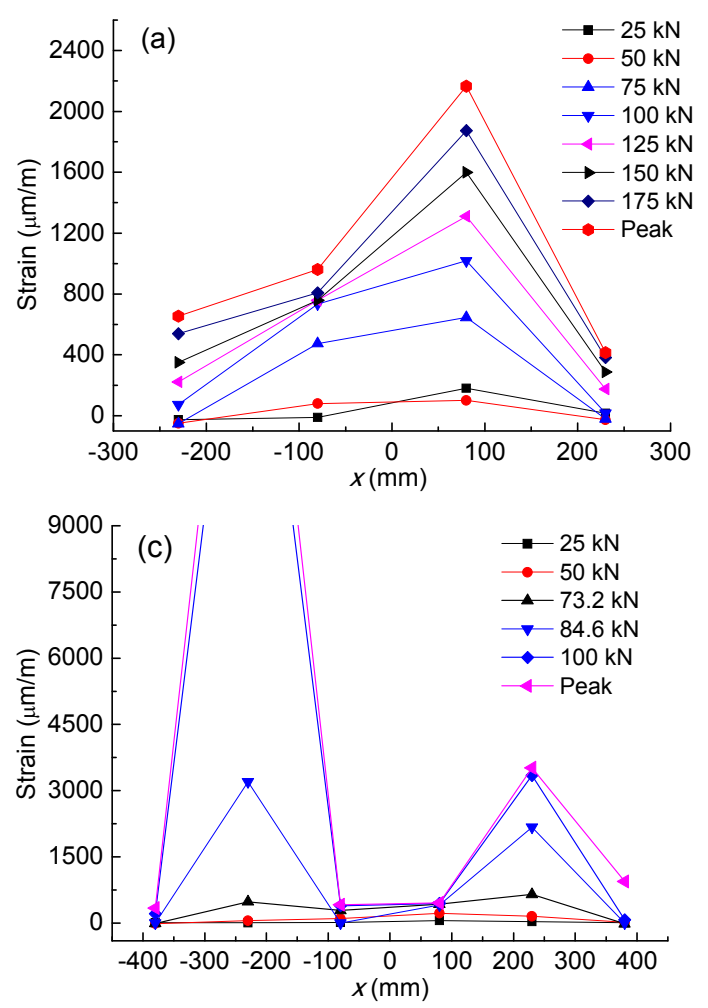

For the slender beam $\mathrm{C} 3-\mathrm{wm}$, the formation of a principal inclined crack resulted in a drastic increase in stirrup strain owing to the redistribution of shear stress. The shear stress carried by aggregate interlock action was transferred to the transverse rebar. Moreover, the crack width rapidly increased after the formation of the principal diagonal crack, resulting in a sharp increase in tensile strain of the stirrup intersecting with this crack. However, regardless of the failure mode, in RUHTCC beams the stirrup strain increased in a relatively gentle way during loading. This can be explained as follows. In RUHTCC beams, diagonal cracks propagated in a stable manner and had a small opening. Also, no principal diagonal crack showing an abrupt increase in width appeared prior to the peak load. Therefore, a relatively stable development of stirrup strain is obtained under these conditions.

However, for RC short beams, the stirrup strain showed no sharp increase although there was a principal diagonal crack formed in the beam web (Fig. 8a). Note that only two pieces of stirrup were arranged in each shear span of the short beams, one close to the side of the support plate and the other close to the
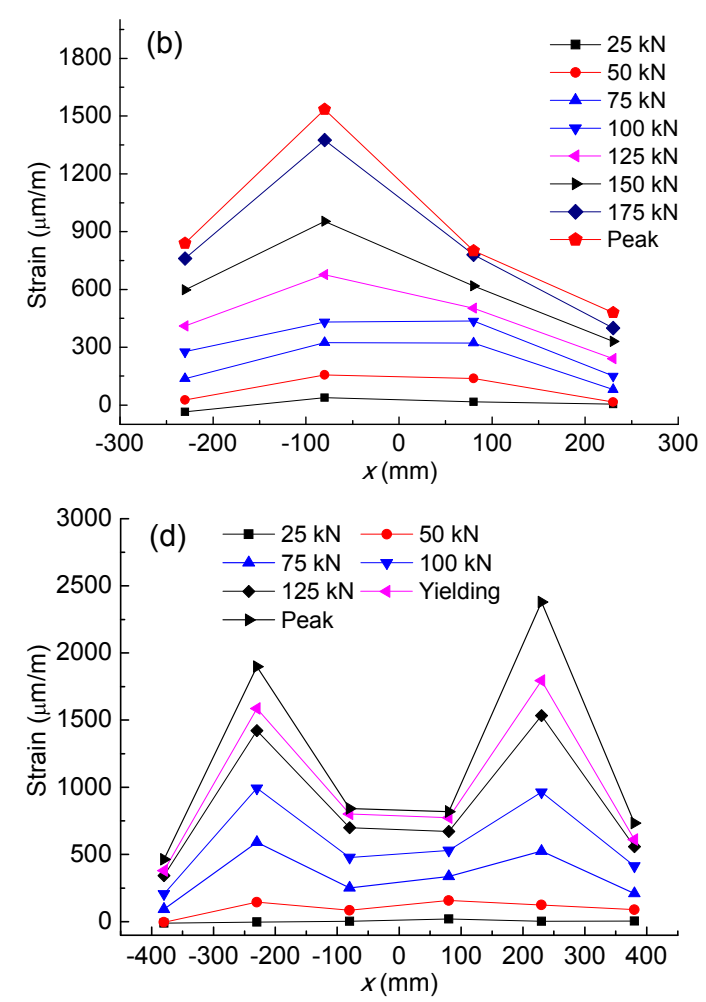

Fig. 8 Evolution of stirrup strain with the applied load for four representative beams (a) C2-wm; (b) U2-wm; (c) C3-wm; (d) U3-wm. $x$ is the distance from the stirrup location to the mid-span 
side of the loading plate. This implies that the stirrups may intersect with the ends of the principal inclined crack which opened mainly between the two stirrups. Thus, the stirrup showed a gentle strain increase and no yielding was observed.

Table 3 summarizes the maximum tensile strain $\left(\varepsilon_{\mathrm{w}}\right)$ of stirrups at the peak load or at the flexural yielding of beams. The tension strain of a strain gauge in beam C3-wm was beyond the upper bound at the peak load due to a rapid opening of the principal diagonal crack intersecting with the stirrup. Moreover, the maximum stirrup strain $\varepsilon_{\mathrm{w}}$ of RUHTCC beams was lower than that of RC comparison beams with the same parameters. This may have resulted from the fine deformation compatibility between the stirrups and UHTCC after the shear cracking. As expected, the $\varepsilon_{\mathrm{w}}$ at the point of yielding of RUHTCC beams with an ald of 3.08 decreased with the increase in stirrup ratio owing to the reduced contribution of stirrups when subjected to similar flexural yielding loading.

\subsection{Cracking and ultimate shear strength}

Generally, nominal shear stress can be calculated by

$$
v=\frac{V}{b d},
$$

where $V$ is the shear force at the calculated section, and $b$ is the width of the cross section. The cracking shear strength $v_{\text {cr }}$ denotes the nominal shear stress at the shear cracking, and the ultimate shear strength $\left(v_{\mathrm{u}}\right)$ corresponds to the shear stress at the ultimate shear force $\left(V_{\mathrm{u}}\right)$. Note that the shear stress at the ultimate state of beams failing in flexure and flexure-shear cannot represent the true shear capacity, because the yielding of longitudinal reinforcement dominates the ultimate load level. However, for uniform and convenient expression, the ultimate shear strength $v_{\mathrm{u}}$ is also used for these beams.

Table 3 summarizes the calculated results. The cracking shear strength of $\mathrm{RC}$ beams ranged from 1.53 to $1.89 \mathrm{MPa}$, and that of RUHTCC beams from 1.51 to $1.94 \mathrm{MPa}$ (Table 3). It seems that the short beams have a cracking shear strength about 0.2 $0.3 \mathrm{MPa}$ larger than that of slender beams. Moreover, the stirrups provided had little influence on the shear cracking strength, except for beam U3-wl, because of the slight shear contribution of web reinforcement up to the shear cracking.

Fig. 9 shows the variation in ultimate shear strength with the shear-span ratio and stirrup ratio. The ultimate shear strength of short beams was far larger than that of slender beams, regardless of the RC beams and RUHTCC beams. This phenomenon arises mainly from different shear transfer mechanisms. The tied-arch model in short beams is governed by the crush of the inclined strut and compression zone under the loading plate. However, the beam action model in RC slender beams and the truss model in RUHTCC slender beams are dominated by both the tension properties of the beam web and the compression capacity of the compression zone under the loading plate. Obviously, the tied-arch system is expected to show a higher shear resistance than beam action and truss systems.

For short beams, the ultimate shear strength was similar regardless of the type of matrix materials and stirrup ratios. The similar compression strength of UHTCC and concrete results in a similar load carrying capacity of a tied-arch system for RUHTCC and $\mathrm{RC}$ beams without stirrups. In addition, the confinement effect of stirrups with a spacing of $150 \mathrm{~mm}$ gave little improvement in compressive strength of the inclined strut and top compression zone. As suggested in Chinese code GB50010-2010 (SAC, 2010), only if a spiral or welded stirrup with a spacing between $40 \mathrm{~mm}$ and the maximum value of $80 \mathrm{~mm}$ and $d_{\text {cor }} / 5$ ( $d_{\text {cor }}$ is the diameter of the core section inside the stirrup) is provided for the circle column, the strengthening effect of the stirrup may be considered.

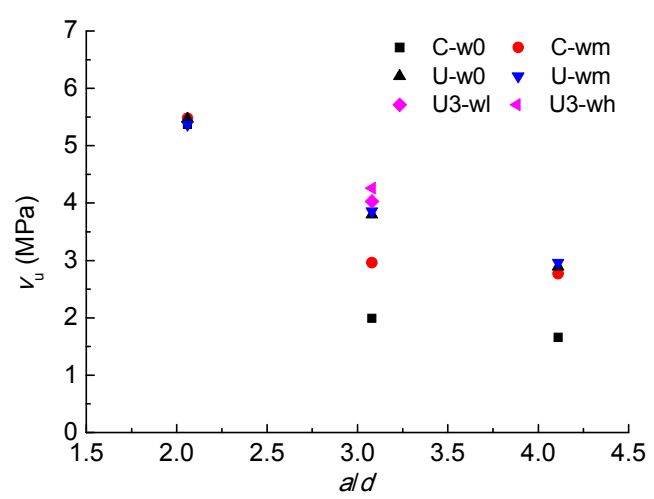

Fig. 9 Change in ultimate shear strength with the shearspan ratio and stirrup ratio 
For slender beams, the ultimate shear strength of RUHTCC beam U3-w0 was about $3.80 \mathrm{MPa}$ (Table 3), which is far larger than the $2.96 \mathrm{MPa}$ of $\mathrm{RC}$ beam $\mathrm{C} 3$-wm with a stirrup ratio of $0.37 \%$. This experimental result fully demonstrates the outstanding shear resistance of UHTCC, the use of which can save at least $0.37 \%$ on web reinforcement. Majdzadeh et al. (2006) indicated that the composite use of stirrups and FRC in slender beams resulted in a synergic influence on shear resistance. However, with respect to the RUHTCC slender beams in the present tests, the ultimate shear strength of beams with stirrups was almost comparable to that of beams without stirrups. This implies that there is no synergic effect between UHTCC and stirrups. For RUHTCC beams with an ald of 3.08 , the use of a $0.25 \%-0.55 \%$ stirrup ratio resulted in flexural yielding of longitudinal reinforcement, and the yielding load of beams U3-wl, U3-wm, and U3-wh was similar to the ultimate load of beam U3-w0. For RUHTCC beams with an a/d of 4.11, flexural yielding occurred even if no transverse rebar was provided. Consequently, a small load increase after the yielding of reinforcement is expected to lead to a slight improvement in shear stress at the ultimate failure.

Generally, the use of the minimum transverse stirrup ratio is necessary to avoid sudden shear failure after shear cracking of plain RC beams. However, for reinforced FRC beams with a depth below $610 \mathrm{~mm}$, a provision is suggested by ACI 318-08 (ACI, 2008) that a $0.75 \%$ volume fraction of deformed steel fiber can be used as the minimum web reinforcement when subjected to a factor shear stress between $\Phi(1 / 12) f_{\mathrm{c}}{ }^{\prime}$ and $\Phi(1 / 6) f_{\mathrm{c}}^{\prime}$, where $f_{\mathrm{c}}^{\prime}$ represents the cylinder compressive strength, taken as $0.79 f_{\text {cu }}$ (Cheng et al., 2008). This is attributed mainly to the superior shear resistance with the low bound of $0.3 f_{\mathrm{c}}{ }^{(1 / 2)} \mathrm{MPa}$ for SFRC beams with a fiber volume fraction no lower than $0.75 \%$ (Parra-Montesinos, 2006). In the case of RUHTCC beams without stirrups studied here, the slender beams showing a final shear failure had an ultimate shear strength of $0.48 f_{\mathrm{c}}{ }^{\prime(1 / 2)}-0.63 f_{\mathrm{c}}{ }^{\prime(1 / 2)} \mathrm{MPa}$ and the short beams $0.86 f_{\mathrm{c}}{ }^{\prime(1 / 2)} \mathrm{MPa}$. The low bound $0.48 f_{\mathrm{c}}{ }^{(1 / 2)}$ of the shear resistance of RUHTCC beams without stirrups is higher than the $0.3 f_{\mathrm{c}}{ }^{\prime(1 / 2)}$ of SFRC beams. Moreover, the ratio of $v_{\mathrm{u}} / v_{\mathrm{cr}}$ is another key factor determining shear behavior after shear cracking. It is assumed that the minimum stirrup ratio may not be required if the value of $v_{\mathrm{u}} / v_{\mathrm{cr}}$ is beyond 1.30, implying an adequate capacity to prevent abrupt collapse (Ozcebe et al., 1999). For RUHTCC beams without stirrups, the calculated $v_{\mathrm{u}} / v_{\text {cr }}$ shown in Table 3 ranges from 1.77 to 2.82 , which is far larger than 1.30. Therefore, based on these two points, UHTCC used as the matrix of beams can substitute for the minimum web reinforcement of RUHTCC beams.

\section{Shear mechanism of RUHTCC beams}

RUHTCC beams show a shear transfer mode different from that of RC beams. The shear of RC beams is resisted mainly through the shear resistance of the matrix in the compression zone, the aggregate interlocking action along the diagonal crack and the doweling action of longitudinal reinforcement. However, for RUHTCC beams, the use of refined sand as the aggregate of UHTCC results in complete loss of aggregate interlocking action. Instead, the bridging connection action of fibers across diagonal cracks plays an important role in shear transfer of RUHTCC beams. The doweling action is greatly enhanced due to the fine interface bond and deformation compatibility between UHTCC and the reinforcement. Therefore, the shear of RUHTCC beams is carried by UHTCC in the compression zone, reinforcing fibers bridging across inclined cracks and the improved doweling action of the reinforcement. In addition, the direct shear contribution of web reinforcement is important for beams with stirrups. Fig. 10 shows the shear transfer mode in the inclined section for RUHTCC beams.

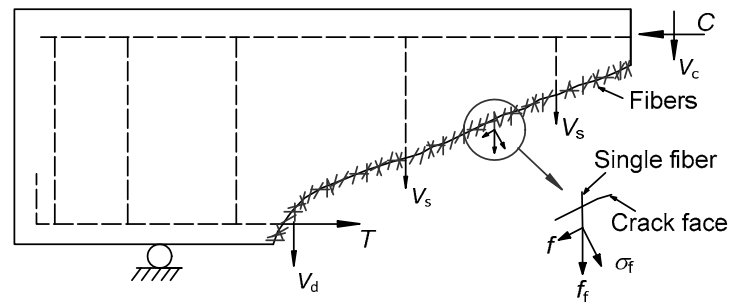

Fig. 10 Shear transfer mode in the inclined section for RUHTCC beams

The shear mechanism varies with the shear-span ratio and the type of matrix materials. For RC beams without stirrups, the shear mechanism can be explained by the cantilever teeth-arch model with a tied 
rebar. The cantilever teeth (representing the beam action mechanism) carry most of the shear for beams with a shear-span ratio larger than 3.0 , whereas the tied-arch (denoting the arch action mechanism) transfers most of the shear for beams with a shearspan ratio lower than 2.0.

For RUHTCC slender beams without stirrups, the cantilever teeth model seems to be inappropriate. The cracked UHTCC web (Fig. 4) can still be considered as a whole due to the remaining tensile stress across the diagonal cracks and a small crack opening. UHTCC can carry both tensile and compressive stress, and UHTCC web subjected to tensile stress can serve as a web stirrup arranged diagonally. Considering the diagonal crack extension length of beam U3-w0 failing in typical shear (Fig. 4c), it seems that an arch-truss model is reasonable to represent the shear mechanism of RUHTCC beams. In this model, the inclined tension and compression members are both composed of UHTCC web, and the compression and tension chord members represent UHTCC in the compression zone and the longitudinal tension rebar, respectively. For RUHTCC slender beams with stirrups, another truss model with two types of tension web members is used to represent the shear mechanism. In addition to the stirrup as a web member, UHTCC web between adjacent stirrups can be used as an inclined tension web member. Fig. 11 shows the shear models of RUHTCC beams.

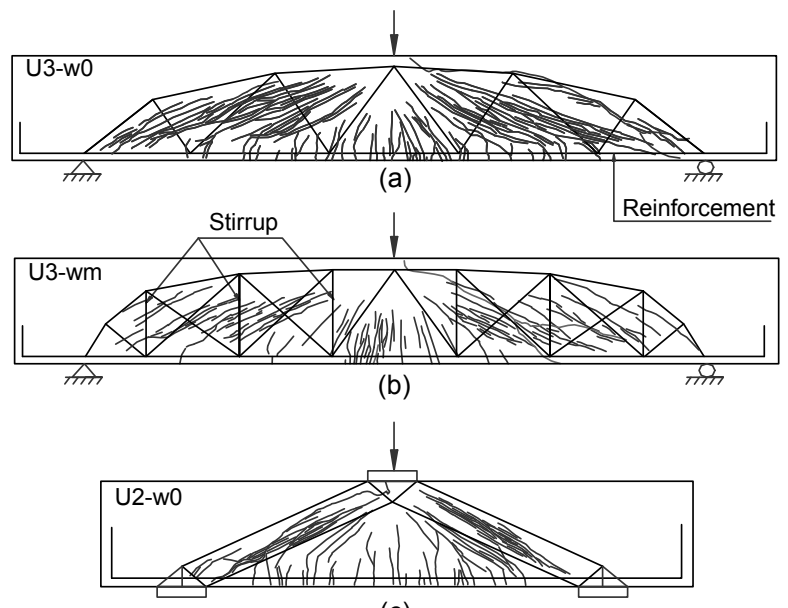

(c)

Fig. 11 Shear transfer mechanism of RUHTCC beams (a) Truss model for slender beams without stirrups; (b) Truss model for slender beams with stirrups; (c) Tied-arch model for short beams
For RUHTCC short beams with a shear-span ratio lower than 2.0 , the shear transfers mainly by the tied-arch model. The complete tied-arch model can be obtained only if there is full debonding between the matrix of beams and the longitudinal rebar. However, this phenomenon cannot occur for RUHTCC beams because the fine deformation compatibility ensures the interface bond between UHTCC and reinforcement. All the diagonal cracks in the flexural-shear zone extend almost to the compression zone under the loading point (Fig. 4a). In other words, the tensile stress of longitudinal reinforcement in the inclined section is governed by the moment at the mid-span location. Consequently, the stress gradient of the longitudinal reinforcement at different locations is expected to be very small. Based on this point, the shear mechanism can be represented by a tied-arch model in which the inclined compression strut is composed of UHTCC web and the longitudinal rebar is used as a tension chord member (Fig. 11c).

In this study, qualitative analysis and description was applied only to the arch-truss model for RUHTCC slender beams without and with stirrups, and the tied-arch model for RUHTCC short beams. But the detailed configuration of these models used to predict the shear strength of RUHTCC beams is insufficient in relation to, for example, the size and spacing of UHTCC tension and compression web members, the inclined angle of web members, and the mechanical behavior and failure criteria of UHTCC web and chord members. Therefore, further experimental and theoretical studies are greatly needed.

\section{Conclusions}

In this study, the shear properties of RUHTCC beams with different shear-span ratios and web reinforcement ratios were investigated through flexural tests under a concentrated loading at the mid-span location. The experimental results reported mainly concern the shear crack characteristics, loaddeflection behavior, stirrup behavior, shear strength, and shear mechanism. Based on the results reported, the following conclusions are drawn:

1. RUHTCC beams showed an apparent diagonal multiple-cracking pattern regardless of shear-span ratios and web reinforcement ratios, demonstrating the prominent crack control capacity of UHTCC in 
shear. No interface splitting crack formed along longitudinal reinforcement due mainly to the bridging action of fibers across diagonal cracks and the fine deformation compatibility between UHTCC and rebar of RUHTCC slender beams and the confinement effect of the support for all the short beams.

2. RUHTCC beams showed a stable crack evolution mode. The maximum shear crack width was merely $0.3 \mathrm{~mm}$ when approaching the ultimate load, and within $0.1 \mathrm{~mm}$ at the service load, which satisfies the crack width demand in harsh environments. The total diagonal crack opening was similar in RUHTCC and RC beams with the same variation parameters, which indicates the excellent crack dispersion capability of UHTCC in shear.

3. For RUHTCC beams with a $3.25 \%$ reinforcement ratio and an a/d of 3.08, the use of a small web stirrup ratio of $0.25 \%$ transformed brittle shear failure into ductile flexure-shear failure showing flexural yielding behavior, and a $0.55 \%$ stirrup ratio gave rise to a flexural failure with a ductility index of 5.28. RUHTCC beams with the same reinforcement ratio and an a/d of 4.11 showed a ductile flexure-shear failure even if no transverse rebar was provided, and a configuration of detailing stirrup resulted in final flexure failure with a ductility index of 4.28. However, for RUHTCC short beams, the use of a detailing stirrup did not change the original shear compression failure mode.

4. The stirrup strain of RUHTCC beams develops relatively gently during loading due to the tight diagonal cracking characteristic in beam web.

5. The ultimate shear strength of RUHTCC beams with an a/d of 3.08 and without stirrups was higher than that of RC counterpart beams with a web reinforcement ratio of $0.37 \%$, which further demonstrates the outstanding shear carrying capacity of UHTCC itself. Short beams showed an ultimate shear strength far larger than that of slender beams, due mainly to crush control of the inclined strut and the top compression zone in a tied-arch system.

6. RUHTCC beams without stirrups had a ultimate shear strength of $0.48 f_{\mathrm{c}}^{\prime(1 / 2)}-0.63 f_{\mathrm{c}}{ }^{\prime(1 / 2)} \mathrm{MPa}$, and a ratio of ultimate shear strength to shear cracking strength of from 1.77 to 2.82 . Thus, the use of UHTCC as the matrix of beams can substitute for the minimum web reinforcement.

7. The configuration of web stirrups gave little enhancement to the ultimate shear strength of
RUHTCC short and slender beams. Thus, no apparent synergy in shear resistance between UHTCC and stirrups was apparent for the beams in this study.

8. For RUHTCC beams, except for UHTCC in the compression zone and the improved doweling action of longitudinal reinforcement, fibers bridging across diagonal cracks play an important role in shear transfer rather than aggregate interlocking along the diagonal crack. A tied-arch model can be used to represent the shear mechanism of RUHTCC short beams and a truss model for RUHTCC slender beams. For RUHTCC slender beams, UHTCC web subjected to tension can be considered as inclined tension web members of a truss model.

\section{References}

ACI (American Concrete Institute), 2008. Building Code Requirements for Structural Concrete and Commentary, ACI 318-08. ACI, Farmington Hills, USA.

Ahmed, S.F.U., Mihashi, H., 2007. A review on durability properties of strain hardening fibre reinforced cementitious composites (SHFRCC). Cement and Concrete Composites, 29(5):365-376. [doi:10.1016/j.cemconcomp. 2006.12.014]

Cheng, W., Yan, D., Wang, T., et al., 2008. Reinforced Concrete Structure. China Architecture \& Building Press, Beijing, China (in Chinese).

Dinh, H.H., Parra-Montesinos, G.J., Wight, J.K., 2010. Shear behavior of steel fiber-reinforced concrete beams without stirrup reinforcement. ACI Structural Journal, 107(5): 597-606.

Hou, L.J., Xu, S.L., Zhang, X.F., 2012. Toughness evaluation of ultra-high toughness cementitious composite specimens with different depths. Magazine of Concrete Research, 64(12):1079-1088. [doi:10.1680/macr.11.00186]

Kim, J.H.J., Lim, Y.M., Won, J.P., 2007. Shear capacity and failure behavior of DFRCC repaired RC beams at tensile region. Engineering Structures, 29(1):121-131. [doi:10. 1016/j.engstruct.2006.04.023]

Kim, W., White, R.N., 1999. Shear-critical cracking in slender reinforced concrete beams. ACI Structural Journal, 96(5):757-765.

Kunieda, M., Rokugo, K., 2006. Recent progress on HPFRCC in Japan: required performance and applications. Journal of Advanced Concrete Technology, 4(1):19-33. [doi:10. 3151/jact.4.19]

Kwak, Y.K., Eberhard, M.O., Kim, W.S., et al., 2002. Shear strength of steel fiber-reinforced concrete beams without stirrups. ACI Structural Journal, 99(4):530-538.

Li, H.D., Xu, S.L., Leung, C.K.Y., 2009. Tensile and flexural properties of ultra high toughness cemontious composite. Journal of Wuhan University of Technology-Materials Science Edition, 24(4):677-683. [doi:10.1007/s11595009-4677-5]

Li, V.C., Leung, C.K.Y., 1992. Steady-state and multiple cracking of short random fiber composites. Journal of 
Engineering Mechanics, 118(11):2246-2264. [doi:10. 1061/(ASCE)0733-9399(1992)118:11(2246)]

Li, V.C., Ward, R., Hamza, A.M., 1992. Steel and synthetic fibers as shear reinforcement. ACI Materials Journal, 89(5):499-508.

Li, V.C., Mishra, D.K., Naaman, A.E., et al., 1994. On the shear behavior of engineered cementitious composites. Advanced Cement Based Materials, 1(3):142-149. [doi:10.1016/1065-7355(94)90045-0]

Li, V.C., Wang, S., Wu, C., 2001. Tensile strain-hardening behavior of PVA-ECC. ACI Materials Journal, 98(6):483-492.

Liu, S.G., 2010. The Study on the Workability and Shear Behavior of Fiber Reinforced Self-compacting Concrete. $\mathrm{PhD}$ Thesis, Dalian University of Technology, Dalian, China (in Chinese).

Liu, W., Xu, S.L., Li, Q.H., 2012. Experimental study on fracture performance of ultra-high toughness cementitious composites with $J$-integral. Engineering Fracture Mechanics, 96:656-666. [doi:10.1016/j.engfracmech. 2012.09.007]

Majdzadeh, F., Soleimani, S.M., Banthia, N., 2006. Shear strength of reinforced concrete beams with a fiber concrete matrix. Canadian Journal of Civil Engineering, 33(6):726-734. [doi:10.1139/105-118]

Narayanan, R., Darwish, I.Y.S., 1987. Use of steel fibers as shear reinforcement. ACI Structural Journal, 84(3): 216-227.

Ozcebe, G., Ersoy, U., Tankut, T., 1999. Evaluation of minimum shear reinforcement requirements for higher strength concrete. ACI Structural Journal, 96(3):361-368.

Parra-Montesinos, G.J., 2006. Shear strength of beams with deformed steel fibers. Concrete International, 28(11): 57-66.

SAC (Standardization Administration of the People's Republic of China), 2002. Metallic Materials-Tensile Testing at Ambient Temperature, GB/T228-2002. SAC, Beijing, China (in Chinese).

SAC (Standardization Administration of the People's Republic of China), 2010. Code for Design of Concrete Structures, GB50010-2010. SAC, Beijing, China (in Chinese).

Shahnewaz, M., Alam, M.S., 2014. Improved shear equations for steel fiber-reinforced concrete deep and slender beams ACI Structural Journal, 111(4):851-860. [doi:10.14359/ 51686736]

Shimizu, K., Kanakubo, T., Kanda, T., et al., 2004. Shear behavior of steel reinforced PVA-ECC beams. 13th World Conference on Earthquake Engineering, International Association for Earthquake Engineering (IAEE), Tokyo, Japan, Paper No. 704.

Shuaib, H.A., Ray, B., 1991. Flexural behavior of reinforced high strength lightweight concrete beams. ACI Structural Journal, 88(1):69-77.

Slater, E., Moni, M., Alam, S.M., 2012. Predicting the shear strength of steel fiber reinforced concrete beams. Construction and Building Materials, 26(1):423-436. [doi:10. 1016/j.conbuildmat.2011.06.042]

Suryanto, B., Nagai, K., Maekawa, K., 2010a. Modeling and analysis of shear-critical ECC members with anisotropic stress and strain fields. Journal of Advanced Concrete
Technology, 8(2):239-258. [doi:10.3151/jact.8.239]

Suryanto, B., Nagai, K., Maekawa, K., 2010b. Smeared-crack modeling of R/ECC membranes incorporating an explicit shear transfer model. Journal of Advanced Concrete Technology, 8(3):315-326. [doi:10.3151/jact.8.315]

Swamy, R.N., Bahia, H.M., 1979. Influence of fiber reinforcement on the dowel resistance to shear. ACI Journal Proceedings, 76(2):327-355.

van Zijl, G.P.A.G., 2007. Improved mechanical performance: shear behaviour of strain-hardening cement-based composites (SHCC). Cement and Concrete Research, 37(8): 1241-1247. [doi:10.1016/j.cemconres.2007.04.009]

van Zijl, G.P.A.G., Wittmann, F.H., 2011. Durability of Strainhardening Fibre-reinforced Cement-based Composites (SHCC). RILEM State-of-the-Art Reports, Vol. 4, Springer, the Netherlands.

Xu, S.L., Li, H.D., 2008. A review on the development of research and application of ultra high toughness cementitious composites. China Civil Engineering Journal, 41(6):45-60 (in Chinese).

Xu, S.L., Hou, L.J., Zhang, X.F., 2012. Shear behavior of reinforced ultrahigh toughness cementitious composite beams without transverse reinforcement. Journal of $\mathrm{Ma}$ terials in Civil Engineering, 24(10):1283-1294. [doi:10. 1061/(ASCE)MT.1943-5533.0000505]

\section{中文概要}

\section{题 目: 钢筋增强超高㓞性水泥基复合材料梁的剪切性能 试验研究}

目 的: 揭示不同剪跨比和配䈨率的钢筋增强超高㓞性水 泥基复合材料 (RUHTCC) 梁的抗剪性能, 为超 高韧性水泥基复合材料 (UHTCC) 用于结构关键 抗剪部位提供参考。

方 法: 基于抗剪试验结果, 阐明剪跨比和配箍率对 RUHTCC 梁抗剪性能的影响, 明确 UHTCC 与䈨 筋之间的复合抗剪效应, 揭示 RUHTCC 梁的抗 剪机理。

方 法: 以剪跨比和配箱率为变量参数, 通过 RUHTCC 梁在跨中集中荷载作用下的弯曲试验, 研究 RUHTCC 梁的剪切裂缝形态、荷载-挠度行为、 破坏模式、开裂剪切强度和极限剪切强度等抗剪 性能, 并结合试验结果, 分析 RUHTCC 梁的剪 力传递机理。

结 论: 1. RUHTCC 梁呈现出优良的剪切抗力以及稳态的 斜裂缝扩展过程和多缝剪切开裂行为。2. 配置少 量的箱筋可将典型的剪切破坏转变为较为延性 的弯剪破坏甚至弯曲破坏。然而, 箍筋的配置并 未显著提高 RUHTCC 梁的抗剪能力, 同时耦合 UHTCC 与䈨筋也没有表现出协同抗剪效应。3. 拉 杆-拱模型和桁架-拱模型可用以描述 RUHTCC 短 梁和细长梁的抗剪机理。

关键词: UHTCC; 剪跨比; 䈐筋; 剪切性能; 抗剪机理 